\title{
El control de convencionalidad: aplicación de las medidas internacionales en el ordenamiento interno como estándar de protección a los derechos de las víctimas*
}

\author{
Recibido: 24 de octubre de 2018 • Aprobado: 11 de marzo de 2019 \\ https://doi.org/10.22395/ojum.v18n37a9 \\ Pedro Alfonso Sánchez Cubides* \\ Diego Mauricio Higuera Jiménez ${ }^{* * *}$ \\ Carolina Torres Bernal ${ }^{* * * *}$
}

\begin{abstract}
RESUMEN
En este artículo se presenta una aproximación de carácter académico a las nociones fundamentales del control de convencionalidad ejercido por la Corte Interamericana de Derechos Humanos, se establece, además, una serie de casos relevantes en materia de protección a los derechos de las víctimas. Asimismo, se presenta una relación jurisprudencial sobre los parámetros que ha utilizado la Corte Constitucional colombiana tratándose de justicia transicional.
\end{abstract}

Palabras clave: control de convencionalidad; víctimas; derechos humanos.

\footnotetext{
Artículo de reflexión producto del proyecto de investigación Políticas públicas de educación superior en Colombia, inscrito en la Dirección de Investigaciones de la Universidad Pedagógica y Tecnológica de Colombia (UPTC), Código SGI 2484. Investigadores principales: Diego Mauricio Higuera Jiménez y Pedro Alfonso Sánchez Cubides. Proyecto vinculado al grupo de investigación Primo Levi de la Facultad de Derecho y Ciencias Sociales de la UPTC. Año: 2018.

** Administrador público, Escuela Superior de Administración Pública (ESAP), Bogotá, Colombia, especialista en Planeación y Gestión del Desarrollo Territorial, Universidad Pedagógica y Tecnológica de Colombia UPTC, Tunja, Colombia, magíster en Gobierno Municipal, Universidad Externado de Colombia, Bogotá, Colombia, especialista en Gobierno y Políticas Públicas, Universidad de los Andes, Bogotá, Colombia, doctor en Ciencias de la Educación, UPTC, Tunja, Colombia, posdoctor en Educación, Ciencias Sociales e Interculturalidad, Universidad Santo Tomás, Bogotá, Colombia, docente e investigador de la UPTC, Tunja, Colombia. Correo electrónico: pedro.sanchez02@uptc.edu.co. Orcid: https://orcid. org/0000-0002-7484-4607

*** Abogado, Universidad Santo Tomás, Seccional Tunja, Colombia, magíster en Derecho Público y Ciencia Política, Université Nancy 2, Nancy, Francia, doctor en Derecho, Universidad Externado de Colombia, Bogotá, Colombia, coinvestigador del Grupo Justicia, Derecho y Estado Social de Derecho, director del Semillero de Investigación Veritas Est Font Libertatis. Correo electrónico: higuerajimenez.abogado@ gmail.com. Orcid: https://orcid.org/0000-0002-0086-0065

${ }^{* * * *}$ Estudiante de noveno semestre de Derecho de la Facultad de Derecho y Ciencias Sociales de la Universidad Pedagógica y Tecnológica de Colombia, Correo electrónico: gladys.torres01@uptc.edu. co. Orcid: https://orcid.org/0000-0002-9938-1151
} 


\title{
The Conventionality Control: Appliance of the International Measures for the Internal Ordering as Victims Rights Protection Standard
}

\begin{abstract}
This article presents an academic approach to the fundamental notions of the conventionality control performed by the Inter-American Court of Human Rights. It is established, as well, a series of relevant cases in matters of protection of victims rights. Additionally, a lawmaking relation on the criteria used by the Colombian Constitutional Court in matters of transitional justice.
\end{abstract}

Keywords: conventionality control, victims, human rights.

\section{Controle de convencionalidade: aplicação das medidas internacionais no ordenamento interno como padrão de proteção aos direitos das vítimas}

\begin{abstract}
RESUMO
Neste artigo, apresenta-se uma aproximação de caráter acadêmico das noções fundamentais do controle de convencionalidade exercido pela Corte Interamericana de Direitos Humanos. Ainda, são estabelecidos casos relevantes em matéria de proteção aos direitos das vítimas. Além disso, apresenta-se uma relação jurisprudencial sobre os parâmetros que a Corte Constitucional colombiana vem utilizando em se tratando de justiça de transição.
\end{abstract}

Palavras-chave: controle de convencionalidade; vítimas; Direitos Humanos. 


\section{INTRODUCCIÓN}

En la esfera de protección a los derechos humanos en América se encuentra, como mecanismo para asegurar el cumplimiento de este objetivo, el control de convencionalidad efectuado por la Corte Interamericana de Derechos Humanos (también Corte IDH), mediante el cual se verifica la armonía entre las disposiciones de la Convención Americana de Derechos Humanos y las condiciones internas de los Estados pertenecientes a la OEA. Una tabla comparativa entre los derechos humanos y los derechos fundamentales la desarrollamos en Higuera (2012) y reiteramos en Higuera (2015a), si bien "tanto derechos humanos como derechos fundamentales, son garantías del orden jurídico para asegurar el respeto por la dignidad humana" (Higuera, 2015a, p. 39). Precisamente, a través de este control, la Corte Interamericana ha proferido diversas sentencias sobre los derechos de las víctimas en contextos de transición de guerra a paz. Lo anterior, en el actual contexto colombiano de posconflicto, brinda algunos parámetros importantes en materia de reparación integral, pues este escenario, implica poner en el centro del debate las medidas de reparación integral y los límites que imponen los derechos de las víctimas del conflicto armado a la justicia transicional.

En ese orden de ideas, en primera medida se realiza algunas precisiones conceptuales sobre el control de convencionalidad, sus características y alcance. Posteriormente, se recogen algunos casos sobre justicia transicional en el Sistema Interamericano de protección a los derechos humanos. De igual manera, se recurre a la jurisprudencia colombiana de la Corte Constitucional acerca de las víctimas y sus derechos. La metodología deductiva empleada recurre al análisis documental y jurisprudencial de precedentes, con un método de alcance descriptivo puntualmente sobre los derechos de las víctimas como límites infranqueables a la justicia transicional.

\section{EL CONTROL DE CONVENCIONALIDAD, DERECHOS HUMANOS Y ORDEN JURÍDICO}

\subsection{Control de convencionalidad como materialización de los derechos humanos}

Actualmente, la importancia en la protección a los derechos humanos es resultado de la idea del valor moderno, histórico, cultural y dignificante de los derechos humanos, ya que se trata de uno de los logros más grandes de la civilización sin el cual todos los desarrollos tecnológicos y científicos serían superfluos (Uprimny, 1992). Sin los derechos humanos no existe la idea de proyecto de la humanidad, como sin los derechos fundamentales no existe la idea de Estado democrático (Ramírez, 2003).

No en vano, para la protección de los derechos fundamentales, la democracia misma se ha dotado de instituciones para hacerlos efectivos, particularmente a través del control de constitucionalidad (Eisenmann,1986) el cual, consta de la verificación 
judicial y eventual sanción del desacato de los mandatos de la Carta Magna (Tobo, 2006) vulneración que puede darse por medio de conductas o de normas (Higuera, 2009a, p. 130), ejemplo de un mecanismo judicial ante la primera es la acción de tutela y ante la segunda la acción pública de inconstitucionalidad (Higuera, 2009b, p. 91; Higuera, 2015b). Así mismo, para lograr la protección de los derechos humanos, establecidos en la Convención Americana de Derechos Humanos (CADH) existen organismos como la Comisión Interamericana de Derechos Humanos (CIDH) con funciones consultivas y la Corte Interamericana de Derechos Humanos (Corte IDH) con función contenciosa encargada de sancionar las vulneraciones a los derechos de la CADH cometidas por los Estados o por particulares en complicidad, tolerancia y aquiescencia estatal. Por tanto, la actividad jurisdiccional que ejerce la Corte IDH se realiza por medio del control de convencionalidad sobre conductas y normas. Las decisiones que profieran estos organismos son de carácter obligatorio pues su carácter vinculante deviene de la ratificación de los tratados internacionales y de la aceptación de la competencia contenciosa de la Corte IDH, al respecto esta última ha sostenido que:

En otras ocasiones he cotejado la función de los tribunales internacionales de Derechos Humanos con la misión de las cortes constitucionales internas. Estas tienen a su cargo velar por el Estado de derecho a través del juzgamiento sobre la subordinación de actos de autoridades a la ley suprema de la nación. En el desarrollo de la justicia constitucional ha aparecido una jurisprudencia de principios y valores - principios y valores del sistema democrático- que ilustra el rumbo del Estado, brinda seguridad a los particulares y establece el derrotero y las fronteras en el quehacer de los órganos del Estado. Desde otro ángulo, el control de constitucionalidad, como valoración y decisión sobre el acto de autoridad sometido a juicio, se encomienda a un órgano de elevada jerarquía dentro de la estructura jurisdiccional del Estado (control concentrado) o se asigna a los diversos órganos jurisdiccionales en lo que respecta a los asuntos de los que toman conocimiento conforme a sus respectivas competencias (control difuso) (Corte IDH, 2006a).

En ese sentido, el control de convencionalidad puede ser concentrado en un organismo internacional o difuso a nivel interno, compuesto de un solo órgano (difuso territorial y no competencialmente) o en cabeza de todos los jueces (difuso competenciall $)^{1}$ en sistemas donde se ha reconocido la aplicabilidad de los tratados sobre derechos humanos en el derecho interno, como es el caso de Colombia vía bloque de constitucionalidad (Uprimny, 2006) se trata de un control complementario que integra las características del control difuso y concentrado. Por lo tanto, un juez que inaplica una ley en excepción de inconstitucionalidad, por ejemplo, aplicando la Convención vía bloque de constitucionalidad, es concurrentemente juez constitucional

\footnotetext{
"El Poder Judicial debe ejercer una especie de 'control de convencionalidad' entre las normas jurídicas internas que aplican en los casos concretos y la CIDH. En esta tarea, el Poder Judicial debe tener en cuenta no solamente el tratado, sino también la interpretación que del mismo ha hecho la Corte IDH, intérprete última de la CADH" (Corte IDH, 2006b).
} 
(el cual aplica el bloque de constitucionalidad) y juez convencional, a la par de sus funciones como juez común (civil, penal, laboral, administrativo, etc.) De tal manera que:

Los órganos del Poder Judicial deben ejercer no solo un control de constitucionalidad, sino también de convencionalidad ex officio entre las normas internas y la Convención Americana, evidentemente en el marco de sus respectivas competencias y de las regulaciones procesales correspondientes (Corte IDH, 2006a, párr. 128).

En la jurisprudencia de la Corte IDH se ha señalado en el caso Heliodoro Portugal vs. Panamá, sobre la desaparición forzada de un disidente político del Estado sostuvo que:

179. En el derecho de gentes, una norma consuetudinaria prescribe que un Estado que ha celebrado un convenio internacional, debe introducir en su derecho interno las modificaciones necesarias para asegurar la ejecución de las obligaciones asumidas. En la Convención Americana este principio es recogido en su artículo 2, que establece la obligación general de cada Estado Parte de adecuar su derecho interno a las disposiciones de la misma, para garantizar los derechos en ella reconocidos, lo cual implica que las medidas de derecho interno han de ser efectivas 'principio de effet utile'.

180. La Corte ha interpretado que tal adecuación implica la adopción de medidas en dos vertientes, a saber: i) la supresión de las normas y prácticas de cualquier naturaleza que entrañen violación a las garantías previstas en la Convención o que desconozcan los derechos allí reconocidos u obstaculicen su ejercicio, y ii) la expedición de normas y el desarrollo de prácticas conducentes a la efectiva observancia de dichas garantías (Corte IDH, 2008).

\section{Sobre el asunto expresa el profesor Rey Cantor:}

El control de convencionalidad es un mecanismo de protección procesal que ejerce la Corte Interamericana de Derechos Humanos, en el evento en que el derecho interno (constitución, ley, actos administrativos, jurisprudencia, prácticas administrativas o judiciales, etc.) es incompatible con la Convención Americana sobre Derechos Humanos u otros tratados -aplicables-, con el objeto de aplicar la Convención u otro tratado, mediante un examen de confrontación normativo (derechos interno con el tratado); en un caso concreto, dictando una sentencia judicial y ordenando la modificación, derogación, anulación o reforma de las normas o prácticas internas, según corresponda, protegiendo los derechos de la persona humana, con el objetivo de garantizar la supremacía de la Convención Americana (2008, p. 47).

De lo expuesto se puede evidenciar que el control de convencionalidad, que se adelanta a propósito de la resolución de un caso concreto, no es un control abstracto a diferencia del control de un tribunal constitucional; además es imposible acudir directamente a la Corte IDH para que anule una norma por considerarla inconvencional, mientras no se conozca una causa concreta con agotamiento de los mecanismos internos. 


\subsection{Sobre los precedentes jurisprudenciales}

El primer precedente que se encuentra en la materia, es el caso La Última Tentación de Cristo vs. Chile por la causa interpuesta con ocasión de la presunta vulneración del derecho a la libertad de expresión y por lo tanto la eventual inconvencionalidad de la censura ${ }^{2}$, amparada esta última en el artículo 19 número 12 de la Constitución Política de Chile de 1980, establece "un sistema de censura para la exhibición y publicidad de la producción cinematográfica" artículo al bajo el cual "los órganos del Poder Judicial prohibieron la exhibición de la película La Última Tentación de Cristo basados en que la 'visión de los personajes presentada en esta obra artística no se adecua a los estándares que en su opinión deberían haberse tenido en cuenta para describirlos'" (Corte IDH, 2001a).

En el caso de Almonacid Arellano vs. Chile se reconoce la competencia para el control de convencionalidad en tal sentido la Corte IDH expresa:

El poder judicial debe ejercer una especie de "control de convencionalidad" entre las normas jurídicas internas que aplican en los casos concretos y la Convención Americana sobre Derechos Humanos. En esta tarea, el Poder Judicial debe tener en cuenta no solamente el tratado, sino también la interpretación que del mismo ha hecho la Corte Interamericana, intérprete última de la Convención Americana (Corte IDH, 2006b).

Una vez probados los hechos alegados por la demanda se condena la vulneración de derechos humanos de la víctima y sus familiares basado en la inconvencionalidad de la ley en la que se ampara la pretendida impunidad

En el presente caso, el Poder Judicial aplicó el Decreto Ley No. 2.191, lo que tuvo como efecto inmediato el cese de las investigaciones y el archivo del expediente, dejando en la impunidad a los responsables de la muerte del señor Almonacid Arellano. De acuerdo a lo anterior, se impidió a los familiares que ejercieran el derecho a ser oídos por un tribunal competente, independiente e imparcial, a través de un recurso efectivo y adecuado que repare las violaciones cometidas en perjuicio de su ser querido y les permitiera conocer la verdad (Corte IDH, 2006b).

Por lo tanto, la Corte IDH resuelve, además de las medidas indemnizatorias, de reparación integral y de carácter simbólico que:

2 En relación con los artículos 1.1 y 2 de la Convención, las normas de derecho interno chileno que regulan la exhibición y publicidad de la producción cinematográfica todavía no han sido adaptadas a lo dispuesto por la Convención Americana en el sentido de que no puede haber censura previa. Por ello el Estado continúa incumpliendo los deberes generales a que se refieren aquellas disposiciones convencionales. 
El Estado debe: i) asegurar que no siga representando un obstáculo para la investigación de la ejecución extrajudicial del señor Almonacid Arellano y para la identificación y, en su caso, sanción de los responsables, y ii) asegurar que el Decreto Ley No. 2.191 no siga representando un obstáculo para la investigación, juzgamiento y, en su caso, sanción de los responsables de otras violaciones similares acontecidas en Chile. El Estado no podrá argüir ninguna ley ni disposición de derecho interno para eximirse de la orden de la Corte de investigar y sancionar penalmente a los responsables de la muerte del señor Almonacid Arellano. Chile no podrá volver a aplicar el Decreto Ley No. 2.191 (Corte IDH, 2006b).

Posteriormente, la Corte IDH reiteró que para la efectiva aplicación de la CADH se debe acatar desde el mandato constitucional hasta las normas de inferior jerarquía, en tal sentido expresa:

La obligación estatal de adecuar la legislación interna a las disposiciones convencionales comprende el texto constitucional y todas las disposiciones jurídicas de carácter secundario o reglamentario, de tal forma que pueda traducirse en la efectiva aplicación práctica de los estándares de protección de los derechos humanos (Corte IDH, 2009).

Es una idea extremadamente relevante pues sostiene que, incluso las constituciones, están sometidas a la Convención ${ }^{3}$. En el fallo no solo se establece la posibilidad de control de convencionalidad sobre las constituciones ${ }^{4}$ sino la modulación de las mismas decisiones "de tal manera, es necesario que las interpretaciones constitucionales y legislativas referidas a los criterios de competencia material y personal de la jurisdicción militar en México, se adecuen a los principios establecidos en la jurisprudencia de este Tribunal, los cuales han sido reiterados en el presente caso" (Corte IDH, 2009). Tratándose de la posibilidad de una convencionalidad condicionada a la interpretación, análoga a la constitucionalidad condicionada que en materia de control de constitucionalidad se da (Tobo, 2006). Por tal razón sostiene la Corte IDH que.

No es necesario ordenar la modificación del contenido normativo que regula el artículo 13 de la Constitución Política de los Estados Unidos Mexicanos. (...) En términos prácticos, la interpretación del artículo 13 de la Constitución Política mexicana debe ser coherente con los principios convencionales y constitucionales de debido proceso y acceso a la justicia, contenidos en el artículo 8.1 de la Convención Americana y las normas pertinentes de la Constitución mexicana (Corte IDH, 2009).

Con todo, el caso se resuelve reprochando una la posibilidad de indultos por violación de derechos humanos.

3 De conformidad con el mencionado artículo 2 de la Convención.

4 Sumando a las clásicas alteraciones de la Constitución, como la mutación y el quebrantamiento la inconvencionalidad. 
Posteriormente en el caso Cabrera García y Montiel Flores vs. México se reitera el precedente establecido en el caso Almonacid Arellanos vs. Chile, igualmente refuerza su idea en las referencias de múltiples tribunales de la región, como La Corte Suprema de Justicia de la Nación de Argentina, Tribunal Constitucional del Perú, Suprema Corte de Justicia de República Dominicana, el Tribunal Constitucional de Bolivia y la Corte Constitucional de Colombia. En tal sentido se puede leer, ha señalado esta última, que en virtud de que la Constitución colombiana señala que los derechos y deberes constitucionales deben interpretarse "de conformidad con los tratados internacionales sobre Derechos Humanos ratificados por Colombia", se deriva "que la jurisprudencia de las instancias internacionales, encargadas de interpretar esos tratados, constituye un criterio hermenéutico relevante para establecer el sentido de las normas constitucionales sobre derechos fundamentales" (Corte Constitucional, 2000).

Tras este análisis, se procede a evaluar la convencionalidad de las normas de fuero militar que puedan resultar violatorias de los derechos humanos. Al respecto, la Corte IDH resalta que el cumplimiento de dichos estándares se da con la investigación de todas las vulneraciones de Derechos Humanos en el marco de la jurisdicción penal ordinaria, por lo que no puede limitar su campo de aplicación a violaciones específicas, tales como la tortura, la desaparición forzada o la violación sexual. El Tribunal recuerda que el artículo 2 de la Convención Americana establece la obligación general de todo Estado parte de adecuar su derecho interno a las disposiciones de la misma para garantizar los derechos en ella reconocidos, lo cual implica que las medidas de derecho interno han de ser efectivas (principio de effetutile) (Corte IDH, 2010a). Por lo tanto, el reconocimiento extensivo y vulneratorio de derechos humanos del fuero militar debe ser considerado inconvencional.

Respecto del caso colombiano, se encuentra la sentencia por el homicidio del senador Manuel Cepeda Vargas, en el caso se condenó la participación del Estado en el genocidio político, la vulneración de derechos a los parientes sobrevivientes y actuaciones ulteriores del gobierno que reiteraron la victimización de los familiares:

En el presente caso, la Corte advierte que habiendo transcurrido 16 años de ocurridos los hechos, el proceso penal continúa abierto, sin que se haya procesado y eventualmente sancionado a todos los responsables, lo cual ha sobrepasado excesivamente el plazo que puede considerarse razonable para estos efectos. A la luz de estas consideraciones y del reconocimiento de responsabilidad del Estado, la Corte da por establecido que el Estado incumplió los requerimientos del artículo 8.1 de la Convención. Sumada a la violación masiva de Derechos Humanos dada por el exterminio de un grupo político se evidencia una actitud hostil de parte del gobierno en su entonces campaña reeleccionista, tanto así que en los elementos de difusión de la reelección en Colombia se difundían contenidos publicitarios donde por ejemplo: un supuesto exmilitante del grupo político de la UP decía: Señor Presidente: yo pertenecía a la UP, me parecía un buen movimiento, pero nos fuimos torciendo, matar por matar 
hacer daño a los demás, matar civiles, eso está mal hecho. Está bien que usted los esté combatiendo, por eso hoy día lo apoyamos a usted con toda la que tenemos (sic.) iAdelante, Presidente! (Corte IDH, 2010b).

En sentencia de la Corte Constitucional se consideró que esa campaña vulneraba derechos fundamentales por lo que se ordenó retractación de la misma. Lo interesante desde la perspectiva de este análisis es que la Corte IDH considera que efectivamente el gobierno colombiano vulneró la Convención Interamericana de Derechos Humanos, pero que la violación fue sancionada por Corte Constitucional la cual concluyó que:

Al sindicar a una persona o a un grupo de personas de matar a civiles y de hacerle daño a los demás, sin aportar el acervo probatorio que justifique afirmaciones de esa magnitud, se traspasan los límites de la libertad de expresión, pues no resulta razonable entender cobijadas tales manifestaciones en el ámbito de protección de la libertad de expresión, por más amplio que éste sea (Corte Constitucional, 2006).

Finalmente, en dicha sentencia la Corte Constitucional ordenó al gerente de la campaña de reelección del presidente que, a través de un comunicado, de manera explícita y pública expresara que esta campaña incurrió en error al difundir, como parte de su estrategia publicitaria, un mensaje cuyo contenido no fue comprobado, no obstante que incluía afirmaciones lesivas del buen nombre y de la honra del señor Iván Cepeda Castro y de sus familiares (Corte Constitucional, 2006).

En tal sentido, se condena la vulneración de derechos humanos con ocasión del genocidio, pero no la vulneración de derechos por parte de la campaña reeleccionista, pues esta fue sancionada en revisión de tutela por la Corte Constitucional, aunque reitera que consiste en una conducta inconvencional por la afectación a la dignidad humana que se da en el caso ${ }^{5}$.

\section{TENSIÓN YALCANCES DEL CONTROL DE CONVENCIONALIDAD}

\subsection{Tensión en el control de convencionalidad}

Tradicionalmente se cree que entre la Corte Constitucional y la Corte IDH existen relaciones pacíficas y armónicas entre ambas corporaciones, pues la Corte Constitucional colombiana constantemente cita en sus fallos sentencias de la Corte Interamericana y al mismo tiempo esta última ve con buenos ojos la jurisprudencia colombiana refiriéndose a conceptos y argumentos del Tribunal Constitucional nacional. Autores

5 La jurisprudencia, en una línea coherente, ha sido reiterada en las sentencias: Boyce y otros vs. Barbados, Heliodoro Portugal vs. Panamá, Comunidad Indígena XákmokKásek vs. Paraguay, Fernández Ortega y otros vs. México, Cantú y otra vs. México, Ibsen Cárdenas e Ibsen Peña vs. Bolivia, Vélez Loor vs. Panamá, Gomes Lund y otros (Guerrilha do Araguaia) vs. Brasil, Gelman vs. Uruguay, Chocrón vs. Venezuela, López Mendoza vs. Venezuela, Fontevecchia y D'Amico vs. Argentina. 
como Hernán Olano (2016) consideran que el control de convencionalidad puede darse a nivel tanto internacional como interno y, cuando se utiliza bien, contribuye a que las fuentes internas e internacionales del derecho vigente en cada Estado puedan aplicarse por todas las autoridades de manera ordenada, lógica, armónica y coherente. Sin embargo, sus fuentes normativas no son idénticas (la Constitución y la CADH), si bien ambas tienen como fin último la dignidad humana, cuando se entra en detalle se evidencia, por ejemplo, cómo en la Constitución colombiana no dice ni cuándo comienza ni cuándo termina el derecho a la vida mientras la CADH dice que se tiene derecho a la vida desde la concepción.

En materia de la pérdida de derechos políticos también hay problemas porque la Constitución colombiana admite que por decisiones (no judiciales) se pueden perder o suspender derechos políticos; mientras, en la Convención se establece que debe ser por orden de un juez, lo cual sugiere una aporía entre las facultades de suspender derechos políticos de la Procuraduría, siendo esta un organismo de control pero de carácter no judicial6. Igualmente, la Carta Política de 1991, señala la posibilidad de realizar juicios de única instancia mientras a nivel convencional existe explícitamente el derecho a impugnar ante el superior jerárquico de acuerdo al artículo 8 de la CADH. No solo al nivel de estas aporías, también hay que señalar que la Convención es del año 69, ingresó al ordenamiento jurídico en el 72 y nunca se surtió respecto de ella control de constitucionalidad ${ }^{7}$.

La Corte Interamericana en la dimensión internacional mediante el control de convencionalidad juzga si determinada normatividad del derecho interno sea de orden constitucional o legal resulta contrario a la $\mathrm{CADH}$, interpretando el artículo segundo de la Convención si en el ejercicio de los derechos y libertades mencionados en el artículo 1 no estuviere ya garantizado por disposiciones legislativas o de otro carácter, los Estados partes se comprometen a adoptar, con arreglo a sus procedimientos constitucionales y a las disposiciones de esta Convención, las medidas legislativas o de otro carácter que fueren necesarias para hacer efectivos tales derechos y libertades. Según lo anterior, en sede convencional se tiene la competencia de examinar cualquier acto jurídico incluyendo la Constitución ${ }^{8}$ cuando de vulneraciones a derechos huma-

6 Ante ello, puede argumentarse que la Procuraduría tiene funciones como juez constitucional al velar por la protección de los derechos reconocidos en la Constitución, sin embargo la naturaleza de la Procuraduría es señalada como organismo de control y no en calidad del poder judicial, de allí que la contradicción surge entre la norma de normas que faculta a la procuraduría para suspender derechos políticos y la Convención Americana quien dispone que únicamente a través de una decisión judicial los derechos políticos pueden ser suspendidos.

7 Actualmente los tratados internacionales ingresan al ordenamiento jurídico nacional tras aprobación mediante ley de la república, control de constitucionalidad previo y directo para su posterior sanción presidencial.

8 Controlar la validez de una norma constitucional es uno de los aspectos más complejos de un sistema jurídico coherente. 
nos se trate, así una norma constitucional que permite la discriminación racial, una ley de censura, un acto de violencia contra civiles es una conducta inconvencional y en ausencia de actuaciones judiciales idóneas a nivel interno el tribunal internacional puede entrar a sancionarlas.

Se debe resaltar que el control de convencionalidad es ejercido indirectamente y concurrentemente como control de constitucionalidad vía bloque de constitucionalidad, por lo cual, toda la jurisdicción del Estado nacional debe aplicar los mandatos constitucionales. Así, una reforma constitucional puede ser declarada inexequible por sustitución de la Constitución haciendo uso de los mandatos de la convención, una ley puede, y ha sido, declarada inexequible total o parcialmente por motivos que incluyen su inconvencionalidad.

Este nuevo fenómeno ha dado origen a diversos cuestionamientos, entre los que se resalta la afectación al concepto tradicional legalista, la idea nacionalista de soberanía, la acusación de afectación a la cosa juzgada y la reevaluación de la idea de supremacía constitucional. En materia de reevaluación al concepto legalista se ha dicho que "se pone en crisis la tradicional concepción de que la ley (creada por el legislativo) es la única fuente del derecho, derrumbándose el aforismo tradicional dura lex sed lex, pues una ley podrá ser dura pero nunca contraria ni a la Constitución Política ni a los Tratados Internacionales sobre Derechos Humanos" (Rodríguez, 2008, p. 109), lo cual va de la mano con la devaluación del valor de la ley a nivel interno para darle cabida al valor de las normas en forma de principios y la carga argumentativa de los funcionarios judiciales

La segunda consecuencia se centra en la idea nacionalista de soberanía donde un tribunal internacional toma decisiones sobre las conductas de un Estado nacional, aunque en realidad el derecho internacional existe por actuación misma de los Estados nacionales, que el derecho internacional está constituido por normas que originariamente fueron producidas mediante actos de los Estados -es decir, de los órganos competentes al respecto, conforme a los órdenes jurídicos de cada Estado-, para regular las relaciones interestatales, y ello, por la vía de la costumbre (Kelsen, 2007, p. 330). La tercera consecuencia es la crítica que se ha realizado respecto del concepto de cosa juzgada y seguridad jurídica; sin embargo, estas no se predican si las partes han violado derechos humanos y conllevan a casos de Impunidad.

El último cuestionamiento está en el cambio de la supremacía constitucional para ser esta reemplazada por la supremacía convencional, el principio de supremacía constitucional comienza a erosionarse, a partir del momento en que el Estado parte de un tratado o una convención internacional que reconoce derechos humanos -por ejemplo la Convención Americana de Derechos Humanos- y adquiere obligaciones 
objetivas erga omnes de respetar y garantizar su libre y pleno ejercicio, y de adoptar las medidas legislativas que fueren necesarias para hacer efectivos tales derechos (1.1 y 2), esto es, de legislar de conformidad con el derecho internacional de los derechos humanos (Rey, 2008, p. 47).

Se considera que, efectivamente, ha cambiado (para bien) la idea legalista de derecho, igualmente, se señala que no existe una afectación a la soberanía por el control de convencionalidad, si este es bien aplicado (violaciones de derechos humanos en defecto de la actuación interna). Asimismo, no se puede alegar cosa juzgada ni seguridad jurídica para promover la impunidad en las causas que se estudian a nivel internacional. Sin embargo, la idea defendida por la doctrina de supraconstitucionalidad no se comparte. En primer lugar, el control de convencionalidad no erosiona la Constitución cuando son complementarias, igualmente no se puede negar que la CADH y el control de convencionalidad que de ella se deriva existe por la autoridad normativa de los Estados firmantes, es decir, por fuerza de sus constituciones, a manera de un bloque de convencionalidad compuesto por las normas de máxima jerarquía en los organismos estatales, al punto que no cualquier choque entre el ordenamiento nacional y el internacional privilegia el segundo, solo en los casos donde es con ocasión de una vulneración de la dignidad humana.

\subsection{Control de convencionalidad y monismo juridico}

Para entender los alcances del control de convencionalidad es indispensable interiorizar sus fundamentos desde el derecho internacional. El control de convencionalidad existe para hacer efectivos los mandatos establecidos a favor de la dignidad humana, como una consecuencia del acuerdo de voluntades entre los Estados miembros, así, se trata de la efectividad de los acuerdos internacionales, pacta sunt servanda, producto de la eliminación de la barrera que existía entre el derecho nacional y el internacional, en desarrollo de la idea kelseniana de monismo jurídico (Kelsen, 2007).

El cumplimiento de los tratados internacionales sobre derechos humanos, sufre en Latinoamérica una especie de traumatismo pues existe una brecha entre la voluntad de suscribir los convenios y cumplirlos efectivamente. De allí que debe optarse por la realización del control de convencionalidad. Esa realidad contraria a los fundamentos mismos de la Convención, la cual establece el deber de promulgar una legislación conforme a los estándares de los derechos humanos, derogar las normas contrarias (principio de armonización) y la realización de un diagnóstico por medio del cual se mida y valore la situación de derechos humanos, lo cual permite ponderar y evidenciar el compromiso en materia de progresividad de los derechos humanos. Igualmente, junto al deber de eficacia de los convenios suscritos, se debe reconocer la pretensión de hacer corresponsales a los Estados en el respeto por las garantías contenidas en 
la convención, este deber oficioso del Estado deja en evidencia el valor normativo del orden internacional'.

Finalmente, existen dos razones que soportan el control de convencionalidad. De un lado, los tratados son constitucionales, es decir, parte del ordenamiento interno por reconocimiento constitucional, pero, por otro lado, las constituciones y demás normas son llevadas a nivel internacional, existiendo dilogía entre la constitucionalización del derecho internacional y la internacionalización del derecho constitucional. Ambas razones se soportan en la idea de soberanía, los pactos internacionales tiene fuerza por autoridad del sistema normativo interno, por lo que no es posible hablar de afectación a la soberanía nacional. Finalmente, la soberanía no está en los gobiernos sino en los ciudadanos y si existe una vulneración a los derechos humanos pues existirá una afrenta al soberano ciudadano, solo tras el haberle fallado sus institucionales nacionales frente a la agresión de su dignidad humana existirá la posibilidad de actuación del organismo internacional ${ }^{10}$. "Después de todo, la prosperidad de una sociedad se mide en el respeto de los derechos humanos y su única meta legítima debe ser la realización de los derechos fundamentales, este será el verdadero progreso del espíritu en una comunidad" (Higuera y Torres, 2018, p. 18).

\subsection{El control de convencionalidad, frente a los derechos de las víctimas}

El derecho fundamental de una víctima a la reparación integral incluye la indemnización por perjuicios materiales e inmateriales (salud, daño a la vida en relación) e incluye igualmente las garantías no patrimoniales como los son la verdad histórica y la garantía de no repetición.

\subsubsection{Corte Interamericana: fallos relevantes frente derechos de las víctimas}

A continuación, se relacionan los precedentes y fallos en materia de víctimas, producto del control de convencionalidad efectuado por la Corte IDH, así, por ejemplo, en el caso de la Masacre Plan de Sánchez vs. Guatemala (2004) se afirma:

9 Así como las constituciones tienen un valor normativo y de ahí existe el control de constitucionalidad.

10 De acuerdo con el derecho internacional, no puede excluirse ninguna materia de las normas establecidas por tratados, fundándose en que esta materia es incompatible con la naturaleza y, especialmente, con la soberanía del Estado en tratado. En otras palabras, la idea de Estado como poder supremo, no está en conflicto con el derecho internacional, porque este es válido para el Estado solo porque lo ha reconocido y, en consecuencia, no es superior a él. Esta idea es bastante compatible con el hecho de que un Estado, al reconocer o aprobar, en virtud de su soberanía, el derecho internacional y así hacerlo parte de su derecho, restringe su soberanía, o sea, su libertad de acción o competencia, al aceptar las obligaciones establecidas por el derecho internacional general y los tratados aprobados por el Estado (Cantor, 2007,103). 
El hecho de que la Corte Interamericana carezca de jurisdicción para determinar violaciones de la Convención contra el Genocidio (1948) no significa que la Corte no pueda tomar en cuenta actos que aquella Convención tipifica como de genocidio, como circunstancias agravantes de violaciones de los derechos protegidos por la Convención Americana sobre Derechos Humanos (con incidencia directa en la determinación de las reparaciones). Para este propósito, no es necesario que dichos actos sean calificados como de genocidio, lo que podría generar dificultades para la aplicación de la normativa de la Convención Americana, que tiene por fin la determinación de la responsabilidad internacional del Estado, y no de individuos (Corte IDH, 2004).

\subsubsection{Corte Constitucional: fallos relevantes frente derechos de las víctimas}

Como reconocimiento de los derechos de las víctimas enunciados reiterativamente, la Corte Constitucional realiza un control de convencionalidad diciendo que: La Corte IDH ha señalado que "el derecho a la verdad se subsume en la obligación de los Estados de esclarecer los hechos y juzgar a los responsables así como el derecho a la justicia emanado de los principios sobre la lucha contra la impunidad" (Corte Constitucional, 2013), aunado a la obligación de investigar, juzgar y condenar a penas adecuadas a los responsables fundamentada en el Pacto internacional de derechos civiles y políticos; en la Convención contra la tortura y otros tratos o penas crueles, inhumanos y degradantes; en la Convención interamericana para prevenir y sancionar la tortura; en la Convención interamericana sobre desaparición forzada de personas, en la Declaración americana de derechos humanos, en la Declaración universal de derechos humanos. Siendo por lo tanto un criterio de la proporcionalidad de una norma el adecuado respeto a las víctimas.

\subsection{El control de convencionalidad en los fallos relevantes, frente a la justicia transicional}

La justicia transicional es entendida como el establecimiento de excepciones a mandatos jurídicos, por ejemplo: la pena de prisión; con el objetivo de superar un estadio crítico y normalmente de vulneración de derechos humanos como se verá en los casos de dictaduras, guerras civiles o golpes de Estado, así el regreso a la democracia o la paz en una nación como situaciones preferibles harán necesario y viable jurídicamente que se establezcan algunas condiciones.

Varias de las condiciones normalmente incluyen rebajas de pena, actos simbólicos de reconciliación y priorización de las investigaciones para identificar solo a los principales responsables. No obstante, dados los avances jurídicos en materia del Estado social de derecho y las garantías internacionales para la promoción y protección de derechos humanos, lo que antes era un mero hecho político -como ocurriese con la desmovilización del M-19 o las leyes del punto final en el Cono Sur-actualmente está sometida a limites jurídicos. Una ley de justicia transicional solo será constitucional si es proporcional (Ley 975 de 2005), igualmente, una reforma constitucional que establezca 
instrumentos para la justicia transicional solo será válida mientras no destruya los elementos esenciales definitorios de una Constitución, es decir, mientras no sustituya la Constitución como se ve en la Sentencia C 579 de 2013. Finalmente, aun en el caso en el que se autoriza la ley y la reforma constitucional, estos pueden ser considerados antijurídicos por contravenir los estándares internacionales. De tal manera que estas normas de carácter transicional son objeto de control de convencionalidad.

\subsubsection{Corte Interamericana: fallos relevantes frente a los derechos frente a la justicia transicional}

En materia de justicia transicional se encuentra un auténtico y directo ejercicio del control de convencionalidad, en el caso de Gelman vs. Uruguay, situación en la cual se renuncia a investigar y sancionar las demandas de las víctimas o sus familiares por las graves violaciones a los derechos humanos y crímenes en el periodo de la dictadura militar. En el mencionado caso se aplicó el control de convencionalidad haciendo referencia a que en el momento en que un Estado es miembro o hace parte de diversos tratados internacionales, todo el organigrama, incluido el poder legislativo, tribunales y jueces, se encuentra regido por la convencionalidad, por lo cual les impera proteger en sus efectos los derechos enmarcados por la convención de forma que no se vean disminuidos por la efectivización de normas contrarias. Con ello, el poder judicial y sus órganos adscritos con el deber de administración de justicia en toda su jerarquización, se encuentra sometidos a ejercer ex officio "un control de convencionalidad", entre la normatividad interna y la Convención interamericana, con evidencia en el conjunto de sus competencias y regulaciones procesales respectivas. En esta tarea, no solo se debe tener en cuenta el tratado a aplicar, si no ir más allá del texto y tener una interpretación que da la misma Corte IDH como intérprete de la Convención.

Por lo dicho anteriormente, la Corte ha ejercido el control de convencionalidad en el caso particular de Nibia Sabalsagaray Curutchet respecto de la ley de caducidad, al establecer que:

El límite de la decisión de la mayoría reside, esencialmente, en dos cosas: la tutela de los derechos fundamentales (los primeros, entre todos, son el derecho a la vida y a la libertad personal, y no hay voluntad de la mayoría, ni interés general ni bien común o público en aras de los cuales puedan ser sacrificados) y la sujeción de los poderes públicos a la ley (Corte IDH, 2011, párr. 239).

Lo que también menciona los límites de la democracia en relación con la protección de derechos fundamentales.

El Estado colombiano tiene el deber de poner en acción los mecanismo medidas necesarias para que nadie se excluido de la protección judicial, tal como lo ha enunciado la Corte IDH en el caso de barrios altos en donde se dejó claro que "las leyes 
de autoamnistía que contribuyan al ocultamiento de los responsables por violaciones de Derechos Humanos y que obstaculicen la investigación y el esclarecimiento de los hechos son incompatibles con la Convención Americana de Derechos Humanos" (Corte IDH, 2001b).

\subsubsection{Corte Constitucional: fallos relevantes frente a los derechos en la justicia transicional}

Ley de víctimas. La Corte Constitucional, al realizar un control de convencionalidad implícito a la Ley 1448 de 2011 (Ley de víctimas y restitución de tierras), dentro de la Sentencia C 781 de 2012 expresa que en relación con la aplicabilidad del derecho internacional de los derechos humanos en el conflicto armado interno (premisa dos), el razonamiento de los intervinientes se basa en las siguientes consideraciones: i) la existencia de un conflicto armado interno en Colombia implica que el DIH resulta aplicable, pero no que sea el único régimen jurídico relevante, ii) los tribunales internacionales reconocen, indistintamente, la aplicación del DIH y el DIHD a todas las personas que se encuentren dentro de un territorio en que existe conflicto, iii) además, el derecho internacional señala que no puede establecerse una muralla entre aquellos a quienes se aplica el DIH (o las normas que tipifican los crímenes de guerra) y las víctimas de violencia sociopolítica, a quienes se aplicarían las disposiciones sobre derechos humanos y se hallarían eventualmente protegidos por normas que aluden a crímenes de lesa humanidad. Ambos sistemas se aplican a todos los habitantes en el territorio, pues es ahí donde tiene lugar el conflicto armado (Corte Constitucional, 2012).

Esta Sentencia afirma que la complementariedad de los sistemas ha sido establecida por diversos tribunales (los intervinientes incorporan un conjunto de referencias a pronunciamientos de la Corte Internacional de Justicia, las Observaciones Generales 29 y 31 del Comité de Derechos Humanos de la ONU, la Corte Europea de Derechos Humanos, la Comisión Africana de Derechos Humanos, la Comisión Interamericana de Derechos Humanos (caso Juan Carlos Abella vs. Argentina) y la Corte IDH, en los cuales se ha destacado el principio de complementariedad entre los sistemas normativos del DIH y el DIDH), para concluir:

Es claro que el derecho internacional de los Derechos Humanos aplica de manera simultánea con el DIH en el marco de un conflicto armado de carácter no-internacional. El DIH es lex specialis sobre los derechos humanos, lo que significa que las violaciones de Derechos Humanos en el contexto colombiano deben ser leídas desde el prisma del DIH (Corte Constitucional, 2012).

Lo que puede ser reasumido afirmándose que no existe duda alguna de que cuando las autoridades públicas se alejan del cumplimiento de los deberes constitucionales asignados a cada una y por mera falencia en su operar, desconocen los tratados internacionales que versan sobre derechos humanos sea por acción u omisión, podrán ocasionar un desplazamiento masivo de la población civil. 
Ley de justicia y paz. Dentro del control de constitucionalidad hecho por la Corte Constitucional en la Sentencia C 370 de 2006 a la Ley 975 de 2005, denominada Ley de justicia y paz, se tiene en cuenta el avance jurisprudencial realizado por la Corte interamericana como institución internacional, la cual establece en su jurisprudencia:

Que el derecho a la verdad se encuentra subsumido en el derecho de la víctima o sus familiares a obtener de los órganos competentes del Estado el esclarecimiento de los hechos y el juzgamiento de los responsables conforme a los parámetros de los artículos 8 y 25 de la Convención Americana (Corte Constitucional,2006).

Marco jurídico para la paz. Dentro del control de constitucionalidad realizado por la Corte Constitucional al Acto Legislativo 01 de 2012, la Corte implícitamente realiza un control de convencionalidad, con la Convención al hacer una comparación y un análisis por lo señalado por la Corte IDH referente a los derechos humanos expresando que implica el deber de los Estados parte organizar todo el aparato gubernamental $y$, en general, todas las estructuras a través de las cuales se manifiesta el ejercicio del poder público, de manera tal que sean capaces de asegurar jurídicamente el libre y pleno ejercicio de los derechos humanos. Como consecuencia de esta obligación los Estados deben prevenir, investigar y sancionar toda violación de los derechos reconocidos por la Convención y procurar, además, el restablecimiento, si es posible, del derecho conculcado y, en su caso, la reparación de los daños producidos por la violación de los derechos humanos (Corte Constitucional, 2013).

\section{CONCLUSIONES}

En materia del control de convencionalidad sobre normas legales, la Corte IDH ha adoptado diversas posibilidades, mandando que se adopte la ley, o que se modifique o que se deje sin efecto. El hecho de que se deje sin efectos es análogo a la declaración que hace un tribunal constitucional. Hasta el momento, tratándose de normas constitucionales, la Corte IDH no ha llegado a ejercer un control de convencionalidad estricto o severo de anulación donde se declare sin efectos un determinado artículo de la Constitución de un determinado país miembro, si bien la competencia se ha declarado y las recomendaciones se han acogido para que se modifique bajo la soberanía del Estado y posteriormente se siga vigilando la integridad del pacto. En este orden de ideas se le ordena al Estado que modifique, y solamente cumplido esto se archiva el proceso, pero la modificación y derogación se da por parte de los órganos legislativos o constituyentes del Estado. El control de convencionalidad existe por autorización y soberanía de los Estados firmantes, pero más relevante aún por la soberanía de los ciudadanos ante un caso de vulneración de su dignidad humana, de allí que los derechos humanos, por la acción u omisión del Estado y frente a la inacción de las instituciones internas, será válida jurídicamente la intervención de 
la Corte IDH para ejercer el control de convencionalidad. Todo lo cual confluye en el amparo y la reivindicación de los derechos humanos.

Finalmente, en esta materia se debe insistir en la jurisprudencia, tanto del sistema nacional como del sistema regional americano de protección a los derechos humanos y concretamente de las víctimas en escenarios de transición deben ser preponderantes y se constituyen límites a las actuaciones institucionales de reparación integral. De allí que la actividad jurisdiccional, tanto de la Corte IDH y de la Corte Constitucional, a través del control de convencionalidad y del control de constitucionalidad respectivamente, conforman herramientas fundamentales en la aplicación de estándares a cerca de las víctimas y sus derechos.

\section{REFERENCIAS}

Congreso de la República. Colombia. (2005). Ley 975 de julio 25 por la cual se dictan disposiciones para la reincorporación de miembros de grupos armados organizados al margen de la ley, que contribuyan de manera efectiva a la consecución de la paz nacional y se dictan otras disposiciones para acuerdos humanitarios. Diario Oficial 45.980 de julio 25 de 2005.

Congreso de la República. Colombia. (2012). Acto Legislativo 1 de julio 31 por medio del cual se establecen instrumentos jurídicos de justicia transicional en el marco del artículo 22 de la Constitución Política y se dictan otras disposiciones. Diario Oficial 48.508 de julio 31 de 2012.

Corte Constitucional. (2000). Sentencia C 010 de enero 19. M. P. Martínez Caballero, A.

Corte Constitucional. (2006a). Sentencia C370 de mayo 18. M. P. Cepeda, M., Córdoba, J., Escobar, R., Monroy, M., Tafur, A. y Vargas, C.

Corte Constitucional. (2006b). Sentencia T 959 de noviembre 20. M. P. Escobar Gil, R.

Corte Constitucional. (2012). Sentencia C 781 de octubre 10. M. P. Calle, M. V.

Corte Constitucional. (2013). Sentencia C 579 de agosto 28. M. P. Pretelt Chaljub, J.

Corte Interamericana de Derechos Humanos. (2001a). Sentencia de febrero 5 para el caso La última tentación de Cristo (Olmedo Bustos y otros) vs. Chile.

Corte Interamericana de Derechos Humanos. (2001b). Sentencia de marzo 14 para el caso Barrios Altos vs. Perú.

Corte Interamericana de Derechos Humanos. (2006a). Sentencia de noviembre 24 para el caso Trabajadores cesados del congreso (Aguado Alfaro y otros) vs. Perú.

Corte Interamericana de Derechos Humanos. (2006b). Sentencia de septiembre 26 para el caso Almonacid Arellano y otros vs. Chile.

Corte Interamericana de Derechos Humanos. (2007). Sentencia de noviembre 20 para el caso Caso Boyce $y$ otros vs. Barbados. 
Corte Interamericana de Derechos Humanos. (2004). Sentencia de noviembre 19 para el caso Masacre Plan de Sánchez vs. Guatemala.

Corte Interamericana de Derechos Humanos. (2011). Sentencia de febrero 24 para el caso Gelman vs. Uruguay.

Corte Interamericana de Derechos Humanos. (2008). Sentencia de agosto 12 para el caso Heliodoro Portugal vs. Panamá.

Corte Interamericana de Derechos Humanos. (2009). Sentencia de noviembre 23 para el caso Radilla Pacheco vs. Estados Unidos Mexicanos.

Corte Interamericana de Derechos Humanos. (2010a). Sentencia de noviembre 26 para el caso Cabrera García y Montiel Flores vs. México.

Corte Interamericana de Derechos Humanos. (2010b). Sentencia de mayo 26 para el caso Manuel Cepeda Vargas vs. Colombia.

Corte Interamericana de Derechos Humanos. (2010c). Sentencia de agosto 24 para el caso Comunidad Indígena Xákmok Kásek Vs. Paraguay.

Corte Interamericana de Derechos Humanos. (2010d). Sentencia de agosto 31 para el caso Rosendo Cantú y otra vs. México.

Corte Interamericana de Derechos Humanos. (2010e). Sentencia de septiembre 1 para el caso Ibsen Cárdenas e Ibsen Peña Vs. Bolivia.

Corte Interamericana de Derechos Humanos. (2010f). Sentencia de noviembre 23 para el caso Vélez loor vs. Panamá

Corte Interamericana de Derechos Humanos. (2010g). Sentencia de noviembre 24 para el caso Gomes Lund y otros ("Guerrilha do araguaia") vs. Brasil.

Corte Interamericana de Derechos Humanos. (2011a). Sentencia de mayo 15 para el caso Fernández Ortega y otros vs. México.

Corte Interamericana de Derechos Humanos. (2011b). Sentencia de julio 1 para el caso Chocrón Chocrón vs. Venezuela.

Corte Interamericana de Derechos Humanos. (2011c). Sentencia de noviembre 29 para el caso Fontevecchia y D'amico vs. Argentina.

Corte Interamericana de Derechos Humanos. (2011d). Sentencia de septiembre 1 para el caso López Mendoza vs. Venezuela

Eisenmann, C. (1986). La justicia constitucional y la alta Corte Constitucional austriaca. París: Económica.

Higuera, D. (2009a). El ejercicio del órgano de control de constitucionalidad en Francia y en Colombia. Principia Iuris, 11(11), 137-159.

Higuera, D. (2009b). Estudio integrado de la legitimidad en la Corte Constitucional colombiana. Principia Iuris, 12(12), 91-120. 
Higuera, D. (2012). Bloque de constitucionalidad en Colombia: jurisprudencia y doctrina. Madrid: Editorial Académica Española.

Higuera, D. (2015b). Le contrôle de constitutionnalité en France et en Colombie. París: Editions Universitaires Européennes.

Higuera, D. (2015a). Protección de la dignidad humana: control de constitucionalidad e implementación de mecanismos internacionales. Bogotá: Editorial Ibáñez.

Higuera, D. y Torres, G. (2018). El control de convencionalidad como mecanismo de protección a los derechos de las víctimas en el caso colombiano. En D. Higuera, A. Silvera y J. Ortega (Comps.), Límites jurídicos de los Acuerdos de Paz: límite constitucional e internacional en las modificaciones normativas (pp. 12-38). Barranquilla: Sello Editorial Corponiamericana.

Kelsen, H. (2007). Teoría pura del derecho. Ciudad de México: Porrúa.

Organización de los Estados Americanos. (1969). Convención Americana sobre Derechos Humanos (CADH) suscrita en San José de Costa Rica el 22 de noviembre de 1969, en la Conferencia Especializada Interamericana sobre Derechos Humanos. Recuperado de https://www.cidh.oas.org/ Basicos/Spanish/Basicos2.htm

Olano, H. (2016). Teoría del control de convencionalidad. Estudios Constitucionales, 14(1), 61-94.

Ramírez, G. (2003). Los límites a la reforma constitucional y las garantías -límites del poder constituyente: los derechos fundamentales como paradigma. Bogotá: Universidad Externado de Colombia.

Rey, E. (2008). Control de convencionalidad de las leyes y derechos humanos: homenaje a Héctor Fix-Zamudio. Ciudad de México: Porrúa.

Rodríguez, C. (2008). La decisión judicial: el debate Hart-Dworkin. Bogotá: Universidad de los Andes y Siglo del Hombre.

Tobo, J. (2006). La Corte Constitucional y el control de constitucionalidad en Colombia. Bogotá: Ibáñez.

Uprimny, R. (1992). La dialéctica de los derechos humanos en Colombia. Bogotá: Fundación Universitaria Autónoma de Colombia.

Uprimny, R. (2006). Hay que mantener la tutela contra sentencias. Recuperado de: https://www. dejusticia.org/que-hacer-con-la-tutela-contra-sentencias/ 